\title{
Prevalence of chronic bronchitis in a rural community of the Hill Region of Nepal
}

\author{
MRIGENDRA RAJ PANDEY
}

From the Department of Medicine, Bir Hospital, and the Institute of Medicine, Tribhuvan University, Nepal

ABSTRACT A house to house survey of everyone aged 20 years and above living in a rural community in the Hill Region of Nepal, situated about $16 \mathrm{~km}$ outside Kathmandu city, was conducted to determine the prevalence of chronic bronchitis and cor pulmonale. Of the total eligible population, $2826(95.5 \%)$ were interviewed. Chronic bronchitis was diagnosed according to the British Medical Research Council criteria, and emphysema and cor pulmonale according to the World Health Organisation expert committee criteria. The crude prevalence of chronic bronchitis was found to be $18.3 \%$. The prevalence rate of chronic bronchitis was similar in men and women, whereas in most parts of the world much lower rates have been recorded in women. Study of a random sample of 85 individuals with chronic bronchitis showed that $57 \cdot 4 \%$ had evidence of airways obstruction, whereas $15.8 \%$ of a representative sample $(n=111)$ of the surveyed population (excluding those with chronic bronchitis) showed evidence of airway obstruction. Of 516 subjects diagnosed as having chronic bronchitis, 382 were subsequently investigated in hospital, 134 having declined further investigation. The diagnosis was confirmed in most of the patients $(93.2 \%)$ who were investigated. Other diseases played an insignificant part in the production of the observed high prevalence rates of chronic bronchitis. Of the 382 patients studied in hospital, 87 had emphysema and 42 had cor pulmonale, yielding overall prevalence rates for these two conditions of at least $3.1 \%$ and at least $1.5 \%$ respectively.

Chronic bronchitis presents general practitioners all over the world with one of their most frequent problems, but little has been done to assess the magnitude of this problem in Nepal. A survey of various types of heart diseases in Kathmandu from the records of 1788 patients admitted to Bir Hospital, Kathmandu with cardiac disease from 1969 to 1975 indicated a very high proportion of cor pulmonale $(46 \%) .^{1}$ As hospital statistics do not give a true picture of chest disease in the total population, a study was conducted to determine the prevalence of chronic bronchitis and cor pulmonale in a rural community outside Kathmandu city, Nepal.

\section{Methods}

\section{STUDY POPULATION}

The study area consisted of two contiguous villages, Sundarijal and Bhadrabas, situated on the edge of

\footnotetext{
Address for reprint requests: Dr MR Pandey, PO Box 2587, 1/257 Thapathali, Kathmandu, Nepal.
}

Accepted 4 January 1984 the Kathmandu valley, about $16 \mathrm{~km}$ north of the city centre, at an altitude of $1460 \mathrm{~m}$ above sea level. This area is totally free from industrial and general atmospheric pollution. The villagers live in small clustered huts, which are poorly ventilated. They are predominantly illiterate farmers with a subsistence economy. Tobacco smoking is very common among the villagers. Fuel for cooking and heating is wood and straw; kerosene, for economic reasons, is not used for these purposes. Domestic smoke pollution is considerable as the houses have no chimneys, and is the only source of pollution. The main reason for selecting this area was the better prospects for cooperation from villagers because of a free clinic run by the Mrigendra Medical Trust at Sundarijal. The terrain and living conditions of the area are typical of rural communities in the Hill Region of Nepal. The eligible population for the purpose of this study comprised everyone aged 20 years and above who was permanently resident in the area.

There were 1156 houses in the two villages with a total population of 6465 . The study population as defined numbered 3203 . Of these, 244 were 
excluded as they were employed away from Kathmandu and had been away from their homes for more than a year. There remained 2959 people in the final study population. Of these, $2826(95 \cdot 5 \%)$ were screened. Of the remainder $127(4.3 \%)$ were repeatedly away from home and six $(0 \cdot 20 \%)$ refused to cooperate.

\section{DATA COLLECTION}

A house to house survey of the study area was carried out and all the eligible subjects were interviewed with a questionnaire adapted from that of the British Medical Research Council (MRC) with slight modifications to suit local conditions. ${ }^{2}$ The questionnaire incorporated demographic information and general information such as smoking habits, location of the kitchen, type of fuel used for cooking and heating, and average time per day spent near the fireplace. It also covered information required for the diagnosis of symptomatic chronic bronchitis as recommended by the MRC. Five teams of two senior medical students acted as interviewers. They were intensively trained in survey methods and had a working knowledge of chronic bronchitis and cor pulmonale before the start of the survey. The questionnaire was thoroughly discussed by the members of the field team to ensure accurate translation, uniform questioning of subjects, and consistent recording of answers by the interviewers. The administration of the questionnaire and the technique of the interviewers were further standardised during a pilot survey conducted in a nearby village. A preliminary census was carried out by means of visits to every house. The work of the enumerators was supervised and checked for completeness and accuracy by the chest specialist, who carried out independent enumeration and interviews of sample households.

A field clinic was set up at the survey site and the interviewers were instructed to refer anyone who had more than an occasional cough and sputum production to the clinic, where the chest specialist interviewed and examined them. After the field clinic examination all the patients fulfilling the MRC criteria for chronic bronchitis were referred to Bir Hospital in Kathmandu city for further evaluation. The additional investigation in the hospital included a chest radiograph, an electrocardiogram, and examination of the sputum for acid and alcohol fast bacilli and of blood for haemoglobin and white blood cell count.

The survey in Sundarijal village was conducted during January-March 1979 and that in Bhadrabas village during January-April 1980 . There were no influenza epidemics or other known factors which differed between the two periods and which might have influenced the prevalence of chronic bronchitis or the amount of fuel burnt for heating in the two study areas.

\section{SPIROMETRY}

\section{Normal sample}

As there had been no study of the normal lung function of the Nepalese population, spirometry was performed with a Vitalograph Model 20.400 S-type dry portable spirometer. One hundred and eleven randomly selected normal subjects aged 20 years and over from the two villages were studied who fulfilled the following criteria: (1) they were life long nonsmokers - that is, those who either had never smoked or had never smoked as much as one cigarette or equivalent a day for as long as a year during their life; (2) they had had no appreciable exposure to domestic smoke pollution-that is, they were either not exposed at all or were exposed to domestic smoke for less than one hour a day; (3) they had no cardiorespiratory symptoms. The use of the equipment and the explanation given to the subjects were thoroughly standardised. At least three maximal forced expirations were made and were accepted only if the tracings were technically satisfactory and had less than 5\% variability. Measurements of forced vital capacity (FVC) and forced expiratory volume in one second $\left(\mathrm{FEV}_{1}\right)$ were made directly from the chart (using the chart correction to BTPS) from the best FVC and FEV 1 of the three tracings regardless of whether they were from the same spirogram. FMEF $25-75$ was calculated from the tracing with the best sum of FEV 1 and FVC according to the Snowbird standard. ${ }^{3}$ Height and arm span were measured in centimetres and weight in kilograms (light clothing being worn). At least five subjects of each sex were studied for each decade of age. A regression equation analysis was performed to reach a prediction formula. All the spirometric tests were performed as recommended by the American Thoracic Society at the Snowbird meeting in $1979 .{ }^{3}$

\section{Sample of cases of chronic bronchitis}

Spirometry was performed in 85 randomly selected cases of chronic bronchitis. A forced expiratory ratio (FEV $/ \mathrm{FVC})$ of $75 \%$ or more was regarded as normal. A decrease in FEV, below the $95 \%$ confidence limit of the predicted value with a forced expiratory ratio of $65-74 \%$ was taken as indicating mild obstruction. A forced expiratory ratio of $50-64 \%$ was regarded as indicating moderate obstruction and below $50 \%$ severe obstruction. Reduction of FVC below the $95 \%$ confidence limit of the predicted value with a normal or above normal forced expiratory ratio was taken as indicating restrictive disease. 
Mild decreases in $\mathrm{FEV}_{1}$ or in forced expiratory ratio plus a greater decrease of FVC was considered as a combined obstructive and restrictive pattern. After the initial three tracings had been made, two inhalations of salbutamol were given at intervals of five minutes and another three tracings were taken after 20 minutes.

\section{Study of representative sample of population}

A representative sample of the population was studied to determine whether there were cases of chronic obstructive lung disease with spirometric abnormalities that did not fulfil the MRC criteria of cough and sputum production. There were 18 wards in the two villages and of these one was selected as a representative sample of the study population on the basis of age and sex distribution, smoking, domestic smoke exposure, and prevalence of chronic bronchitis. There were 191 people aged 20 years and above in this ward, of whom $175(91.6 \%)$ cooperated. Twenty nine of these subjects had chronic bronchitis according to MRC criteria. Spirometry tracings and height, weight, and arm span measurements were made in the remaining 146 subjects.

\section{ANALYSIS AND STATISTICAL METHODS}

Chronic bronchitis was defined as cough and sputum production on most days for at least three consecutive months of two successive years. ${ }^{4}$

Cor pulmonale was diagnosed only in those who showed evidence of definite right ventricular hypertrophy, as recommended by the World Health Organisation Expert Committee criteria. ${ }^{5}$

Emphysema was diagnosed on the basis of radiological criteria ${ }^{5}$ proposed by the same committee.

All statistical comparisons were made with the $\chi^{2}$ test. $P$ values less than 0.05 were considered significant.

\section{Results}

Analysis of the data from the two villages showed that the age and sex distribution, smoking habits, and also the prevalences of chronic bronchitis, emphysema, and cor pulmonale were similar in the two areas (table 1). The data from the two villages were therefore pooled and analysed together.

As more than $97 \%$ of the population have a subsistence economy it was not possible to identify socioeconomic subgroups. Furthermore, ethnic group is not an important factor since the prevalence of chronic bronchitis was not significantly different $(p>0 \cdot 10)$ in the four main groups-namely, Brahmin (23.7\%), Chhetry (18.4\%), Newars (15.3\%), Tamang (22.0\%), and others $(20.6 \%)$.

Eight hundred and two subjects were referred to
Table 1 Characteristics of the two study areas

\begin{tabular}{lll}
\hline & \multicolumn{2}{l}{ Study area } \\
\cline { 2 - 3 } & Sundarijal & Bhadrabas \\
\hline Total population & 1427 & 1399 \\
Male: female ratio & $0.91: 1$ & $0.95: 1$ \\
Mean age (y) & $40 \cdot 14$ & $40 \cdot 32$ \\
(SD) & $(15 \cdot 85)$ & $(15 \cdot 09)$ \\
\% of current smokers & 67.9 & $68 \cdot 8$ \\
$\%$ of past smokers & 5.8 & $4 \cdot 5$ \\
Crude prevalance rates of & 17.8 & 18.7 \\
chronic bronchitis & 17.8 & 3.0 \\
emphysema & 3.2 & 1.9 \\
cor pulmonale & 1.1 & \\
\hline
\end{tabular}

the field clinics for confirmation of the diagnosis of chronic bronchitis by MRC criteria. Six hundred and twenty eight subjects attended and the diagnosis was confirmed in 431 of them. The remaining 174 individuals declined to attend the field clinic. Scrutiny of the original questionnaire sheets permitted the diagnosis of chronic bronchitis to be confirmed according to MRC criteria in 85 of the 174 nonattenders. Thus 516 cases of chronic bronchitis were identified out of a total of 2826 subjects interviewed, yielding a crude prevalence rate for persons over the age of 20 of $18.3 \%$.

Of the 431 individuals with chronic bronchitis seen at the field clinic and invited to attend Bir Hospital, 382 actually reported to the hospital and underwent investigation. Chronic bronchitis remained the diagnosis in 356 subjects $(93.2 \%)$ and $26(6.8 \%)$ individuals had a diagnosis other than chronic bronchitis (table 2).

Table 3 shows the age and sex specific prevalence rates for chronic bronchitis. The crude prevalence rate was found to be $17.6 \%$ among men and $18.9 \%$ among women. The prevalence rate increased significantly with age in both sexes (men- $\chi^{2}=$ $179.08, \mathrm{df}=5, \mathrm{p}<0.0001$; women- $\chi^{2}=151.20$, $\mathrm{df}=5, \mathrm{p}<0.0001)$. There was no significant difference between the overall prevalence of chronic bronchitis in men and women $\left(\chi^{2}=0.696, \mathrm{df}=1, \mathrm{p}\right.$ $>0 \cdot 10$ ) except in the 20-29 and 50-59 age group, where there was a significant female preponderance

Table 2 Final diagnosis in subjects with chronic bronchitis investigated at Bir Hospital

\begin{tabular}{lrr}
\hline Diagnosis & \multicolumn{1}{c}{ No } & \multicolumn{1}{c}{$\%$} \\
\hline Chronic bronchitis & 356 & $93 \cdot 2$ \\
Pulmonary tuberculosis & 5 & $1 \cdot 3$ \\
Acute bronchitis & 3 & 0.7 \\
$\begin{array}{l}\text { Coronary artery disease } \\
\text { with left ventricular }\end{array}$ & 1 & \\
failure & 17 & 0.3 \\
Tropical eosinophilia & 382 & $4 \cdot 5$ \\
$\quad$ Total & 382 & 100.0 \\
\hline
\end{tabular}


Table 3 Prevalence of chronic bronchitis according to age and sex

\begin{tabular}{|c|c|c|c|c|c|c|}
\hline \multirow[t]{2}{*}{ Age group (y) } & \multicolumn{3}{|l|}{ Men } & \multicolumn{3}{|l|}{ Women } \\
\hline & No of persons & No of cases & Prev rate (\%) & No of persons & No of cases & Prev rate (\%) \\
\hline $\begin{array}{l}20-29 \\
30-39 \\
40-49 \\
50-59 \\
60-69 \\
70+\end{array}$ & $\begin{array}{r}454 \\
275 \\
215 \\
193 \\
146 \\
92\end{array}$ & $\begin{array}{l}10 \\
39 \\
41 \\
56 \\
60 \\
36\end{array}$ & $\begin{array}{r}2 \cdot 2 \\
14 \cdot 2 \\
19 \cdot 1 \\
29 \cdot 0 \\
41 \cdot 1 \\
39 \cdot 1\end{array}$ & $\begin{array}{r}455 \\
309 \\
285 \\
192 \\
148 \\
62\end{array}$ & $\begin{array}{l}22 \\
44 \\
60 \\
66 \\
61 \\
21\end{array}$ & $\begin{array}{r}4 \cdot 8 \\
14 \cdot 2 \\
21 \cdot 1 \\
34 \cdot 4 \\
41 \cdot 2 \\
33 \cdot 9\end{array}$ \\
\hline Total & 1375 & 242 & $17 \cdot 6$ & 1451 & 274 & $18 \cdot 9$ \\
\hline $40+$ & 646 & 193 & 29.9 & 687 & 208 & $30 \cdot 3$ \\
\hline
\end{tabular}

Table 4 Results of spirometry

\begin{tabular}{llc}
\hline Degree of obstruction* & No $(\%)$ & $\begin{array}{l}\text { Representative sample of survey } \\
\text { population } \ddagger(n=146)\end{array}$ \\
\cline { 2 - 3 } & $\begin{array}{l}\text { Random sample of those with chronic } \\
\text { bronchitis } \dagger(n=61)\end{array}$ & $123(84 \cdot 2)$ \\
None & $26(42 \cdot 6)$ & $15(10 \cdot 3)$ \\
Mild & $17(27 \cdot 9)$ & $7(4 \cdot 8)$ \\
Moderate & $13(21 \cdot 3)$ & $1(0 \cdot 7)$ \\
Severe & $5(8 \cdot 2)$ & $1(2)$ \\
Obstructive and restrictive combined & &
\end{tabular}

*As defined under "Methods."

tExcluding 24 cases of emphysema or cor pulmonale or both.

$\ddagger$ Excluding 29 cases of chronic bronchitis (with or without emphysema and cor pulmonale).

Table 5 Prevalence of chronic bronchitis in different countries

\begin{tabular}{|c|c|c|c|c|c|}
\hline \multirow[t]{2}{*}{ Authors } & \multirow[t]{2}{*}{ Place } & \multirow[t]{2}{*}{ Ages (y) } & \multirow[t]{2}{*}{ No } & \multicolumn{2}{|c|}{ Prevalence (\%) } \\
\hline & & & & Men & Female \\
\hline $\begin{array}{l}\text { Nepal } \\
\text { Present report } \\
\text { UK }\end{array}$ & Sundarijal and Bhadrabas, Nepal & $20+$ & 2826 & $17 \cdot 6$ & $18 \cdot 9$ \\
\hline College of General Practitioners ${ }^{6}$ & $\mathrm{UK}^{*}$ & $40-64$ & 1569 & 17 & 8 \\
\hline $\begin{array}{l}\text { North America } \\
\text { Ferris and Anderson' (1962) } \\
\text { Sweden }\end{array}$ & Berlin, New Hampshire $\dagger$ & $25-74$ & 1139 & $21 \cdot 6$ & $9 \cdot 4$ \\
\hline Irnell and Kiviloog ${ }^{8}$ (1968) & Uppsala* & $30-64$ & 41679 & $2 \cdot 2$ & $1 \cdot 5$ \\
\hline $\begin{array}{l}\text { Japan } \\
\text { Toyama and Kagawa9 (1977) } \\
\text { India }\end{array}$ & Summary of surveys* & $50-59$ & 22590 & $5 \cdot 8$ & $3 \cdot 1$ \\
\hline $\begin{array}{l}\text { Viswanathan and Singh'0 (1977) } \\
\text { Thiruvengadam" et al (1977) } \\
\text { Africa }\end{array}$ & $\begin{array}{l}\text { Delhi* } \\
\text { Madras* }\end{array}$ & $\begin{array}{l}35-74 \\
50-60+\end{array}$ & $\begin{array}{l}300 \\
523\end{array}$ & $\begin{array}{c}12 \\
2 \cdot 4\end{array}$ & $\begin{array}{l}5 \\
1 \cdot 5\end{array}$ \\
\hline $\begin{array}{l}\text { A Sofica } \\
\text { Sofowora (1977) } \\
\text { Cookson and Mataka'13 (1978) }\end{array}$ & $\begin{array}{l}\text { Nigeria* } \\
\text { Gatoona Zimbabwe* }\end{array}$ & $\begin{array}{l}31-70+ \\
20+\end{array}$ & $\begin{array}{l}1544 \\
4994\end{array}$ & $\begin{array}{l}0.27 \\
1.2\end{array}$ & $\begin{array}{l}0.24 \\
2 \cdot 8\end{array}$ \\
\hline
\end{tabular}

Criteria used for diagnosis of chronic bronchitis: *British MRC; †phlegm four days a week three months a year for three years or more.

(20-29 years: $\chi^{2}=3.99, \mathrm{df}=1, \mathrm{p}<0.05 ; 50-59$ years: $\chi^{2}=10.52, \mathrm{df}=1, \mathrm{p}<0.05$ ).

We identified 87 subjects with emphysema and 42 with cor pulmonale, giving crude prevalence rates of at least $3.1 \%$ and at least $1.5 \%$ respectively for the interviewed population of 2826 . These figures do not take into account the possibility that there may have been other cases of emphysema or cor pulmonale among those who failed to attend the hospital.
Table 4 shows the results of spirometry. Out of 85 randomly selected individuals with chronic bronchitis, 24 had emphysema with or without cor pulmonale and were excluded from the analysis. An obstructive pattern was found in $57.4 \%$ of cases of chronic bronchitis. Only one subject showed reversible obstruction after inhalation of a bronchodilator (increase of $\mathrm{FEV}_{1}$ of more than 15\%). Spirometric study of a representative sample of 175 subjects from the population showed that, after elimination 
of 29 cases of chronic bronchitis, there were 23 with evidence of obstructive disease among the remaining $146(15 \cdot 8 \%)$. In one case obstruction was reversed by bronchodilation.

\section{Discussion}

For epidemiological purposes chronic bronchitis is diagnosed by questionnaire alone. We carried out detailed examinations at the field clinic and in the hospital to try to identify the prevalence of emphysema and cor pulmonale and also to assess the extent to which other lung disease might be responsible for the observed prevalence rates of chronic bronchitis. The great majority of patients investigated in hospital were found to have chronic bronchitis and, although a small number of patients had tropical eosinophilia, pulmonary tuberculosis, and acute bronchitis, the numbers are too small to provide much of the explanation of the high prevalence rate of chronic bronchitis.

The prevalence of emphysema and cor pulmonale might have been underestimated as the diagnosis could be made only in the hospital. Out of 431 individuals with chronic bronchitis referred to the hospital, only 382 attended. It is possible that there were a few cases of emphysema and cor pulmonale among the 41 who failed to attend the hospital and among the 85 with chronic bronchitis who failed to attend the field clinic.

Most of the standard work on chronic bronchitis in the past has used MRC criteria for diagnosis. We used the MRC criteria to enable us to compare our findings with those obtained in other countries (table 5).

The age specific prevalence rates in the present study are higher than those reported from most other countries, especially among women. An exception is the study by Woolcock and Blackburn ${ }^{14}$ carried out in the highlands of Papua New Guinea, in which prevalences of $36 \%$ among men and $37 \%$ among women were recorded. These high rates may, however, be partly due to the generous criteria used to diagnose chronic bronchitis. Anderson ${ }^{15}$ in a study of the lowland population of the same country reported prevalence rates of $10 \%$ and $7 \%$ among men and women respectively. A striking feature of the present study is the more or less equal prevalence rate of chronic bronchitis in men and women, whereas most other studies show much lower rates among women. ${ }^{6-10}$ Interestingly a significantly higher prevalence rate was found in women aged 20-29 than in men of the same age. These differences are probably related to the exposure of women in rural areas to domestic smoke pollution as most of the cooking in the villages is done by women in their teens and twenties. The relationship between chronic bronchitis and domestic pollution is the subject of another paper ( $p$ 337).

The rise in prevalence of chronic bronchitis with increasing age seen in this study is in conformity with the findings of surveys carried out in Britain. ${ }^{16-19}$ A relationship between age and the prevalence rate of chronic bronchitis was not, however, observed in certain surveys conducted in United States, ${ }^{20-22}$ Canada, ${ }^{23}$ and Australia. ${ }^{24}$ British workers postulated that the age gradient for chronic bronchitis seen in their studies may be due to industrial air pollution in their cities. ${ }^{16}{ }^{18}$ But our observations indicate that an age gradient can also be seen in a rural population with no exposure to industrial pollution.

In a random sample of patients with chronic bronchitis (without emphysema or cor pulmonale), $57.4 \%$ showed evidence of airway obstruction. Similarly $15.8 \%$ of a representative sample of the surveyed population (those with chronic bronchitis, emphysema, and cor pulmonale being excluded) showed evidence of airway obstruction. Most of these individuals $(10.3 \%)$ of the sample showed a mildly obstructive spirometric pattern. Fletcher and his colleagues ${ }^{25}$ describe two main disorders - " the obstructive disorder, which may lead to progressive disability, and the hypersecretory disorder, which may sometimes accompany the obstructive disorder" - and they pointed out that "many obstructed men have little or no mucus expectoration, while many with chronic expectoration will never develop significant obstructive disease." The findings of the present study support this view.

I wish to express my most grateful thanks to all the hard working members of the team and also to the superintendent of $\mathrm{Bir}$ Hospital for providing facilities for investigation. The work was supported by grants from the National Council for Science and Technology and the Mrigendra Medical Trust.

\section{References}

I Pandey MR, Ghimire M. Prevalence of various types of heart diseases in Kathmandu. J Nepal Med Assoc 1975;13:37.

${ }^{2}$ Medical Research Council. Standardized questionnaires on respiratory symptoms. Br Med J 1960;ii:1665.

${ }^{3}$ Gardner RM et al. Snowbird Workshop on Standardisation of Spirometry: a statement by the American Thoracic Society. Am Rev Respir Dis 1979;119:8318.

${ }^{4}$ Medical Research Council. Definition and classification of chronic bronchitis for clinical and epidemiological purposes. Lancet 1965;i:775-9. 
${ }^{5}$ World Health Organisation. Report of an expert committee on chronic cor pulmonale. Geneva: WHO, 1961. (Technical report series, No. 213.)

- College of General Practitioners. Chronic bronchitis in Great Britain: a national survey carried out by the respiratory diseases study group of the college of general practitioners. Br Med J 1961;ii:973-9.

${ }^{7}$ Ferris BG, Anderson DO. The prevalence of chronic respiratory disease in a New Hampshire town. Am Rev Respir Dis 1962;86:165-77.

${ }^{8}$ Irnell L, Kiviloog J. Bronchial asthma and bronchitis in a Swedish urban and rural population. Scand J Respir Dis 1968;suppl 66:1-86.

9 Toyama T, Kagawa J. Prevalence of chronic bronchitis in Japan. In: Viswanathan R, Jaggi OP, eds. Advances in chronic obstructive lung disease: proceedings of the World Congress on Asthma, Bronchitis and Allied Conditions (1974). Delhi: Asthma and Bronchitis Foundation of India, 1977:5-19.

${ }^{10}$ Viswanathan R, Singh K. Chronic bronchitis and asthma in urban and rural Delhi. In: Viswanathan $\mathbf{R}$, Jaggi $\mathrm{OP}$, eds. Advances in chronic obstructive lung disease: proceedings of the World Congress on Asthma, Bronchitis and Allied Conditions (1974). Delhi: Asthma and Bronchitis Foundation of India, 1977:44-8.

"Thiruvengadam KV, Raghava TP, Krishnaswamy KV, et al. Survey of the prevalence of chronic bronchitis in Madras city. In: Viswanathan $\mathbf{R}$, Jaggi OP, eds. Advances in chronic obstructive lung disease: proceedings of the World Congress on Asthma, Bronchitis and Allied Conditions (1974). Delhi: Asthma and Bronchitis Foundation of India, 1977:59-69.

${ }^{12}$ Sofowora EO. Chronic bronchitis and asthma in a Nigerian community. In: Viswanathan R, Jaggi OP, eds. Advances in chronic obstructive lung disease: proceedings of the World Congress on Asthma, Bronchitis and Allied Conditions (1974). Delhi: Asthma and Bronchitis Foundation of India, 1977:36-43.
${ }^{13}$ Cookson JB, Mataka G. Prevalence of chronic bronchitis in Rhodesian Africans. Thorax 1978;33:328-34.

14 Woolcock AJ, Blackburn CRB. Chronic lung disease in the territory of Papua and New Guinea-epidemiological study. Australas Ann Med 1967;16:11-9.

is Anderson HR. Respiratory abnormalities and respiratory capacity in a Papua New Guinea island community. Am Rev Respir Dis 1976;114:537-48.

${ }^{16}$ Fletcher CM, Elmes PC, Fairbairn AS, Wood CH. The significance of respiratory symptoms and the diagnosis of chronic bronchitis in a working population. $\mathrm{Br} \mathrm{Med}$ J 1959;ii:257-66.

${ }^{17}$ Higgins ITT. Tobacco smoking, respiratory symptoms, and ventilatory capacity. $\mathrm{Br}$ Med J 1959;i:325-9.

${ }^{18}$ Holland WW, Reid DD. The urban factor in chronic bronchitis. Lancet 1965;i:455-8.

${ }^{19}$ Rimington J. Chronic bronchitis, smoking and social class. Br J Dis Chest 1969;63:193-205.

${ }^{20}$ Deane M, Goldsmith JR, Tuma D. Respiratory conditions in outside workers. Arch Env Health 1965;10:323.

${ }^{21}$ Holland WW, Stone RW. Respiratory disorders in US east coast telephone men. Am J Epidemiol 1964;82:92.

22 Sharp JI, Paul O, Lepper MH, McKean H, Saxton GA jun. Prevalence of chronic bronchitis in an American male urban industrial population. Am Rev Respir Dis 1965;92:510-20.

${ }^{23}$ Anderson DO, Ferris BG. The Chilliwack respiratory survey. Can Med Assoc J 1963;92:1007.

${ }^{24}$ Read J, Selby T. Tobacco smoking and ventilatory function of the lungs. $\mathrm{Br}$ Med J 1961;ii:1104-8.

${ }^{25}$ Fletcher C, Peto R, Tinker C, Speizer FE. The natural history of chronic bronchitis and emphysema. An eight-year study of early chronic obstructive lung disease in working men in London. Oxford: Blackwell Medical Publications, 1976: ch 7. 